\title{
Electrochemical Behavior, Microstructural Analysis, and Morphological Observations in Reinforced Mortar Subjected to Chloride Ingress
}

\author{
D. A. Koleva, ${ }^{\mathrm{a}, *, \mathrm{z}}$ K. van Breugel, ${ }^{\text {a }}$ J. H. W. de Wit, ${ }^{\mathrm{b}, *}$ E. van Westing, ${ }^{\text {b }}$ \\ N. Boshkov, ${ }^{c}$ and A. L. A. Fraaij ${ }^{\mathrm{a}}$ \\ ${ }^{a}$ Section material Science, Department Civil Engineering and Geosciences, ${ }^{b}$ Corrosion Technology and \\ Electrochemistry Department, Faculty of Materials Science and Engineering, Delft University of Technology, \\ 2628 CD Delft, The Netherlands \\ ${ }^{c}$ Institute of Physical Chemistry, Bulgarian Academy of Sciences, Sofia 1000, Bulgaria
}

\begin{abstract}
The behavior of steel reinforcement was studied using electrochemical impedance spectroscopy (EIS) and polarization resistance (PR) techniques in conditions of chloride-induced corrosion in ordinary Portland cement-mortar specimens immersed in $7 \% \mathrm{NaC}$ for a test period of 120 days and compared to specimens immersed in demineralized water for the same period as reference specimens. This study was an initial phase of ongoing research on electrochemical methods for corrosion protection in reinforced concrete structures and aimed at investigating the applicability of widely accepted techniques as EIS and PR and their possible correlation with structural observations of the bulk matrix, relevant to cement-based materials science and product-layers distribution, to corrosion and further protection. The results indicate that the concept of EIS modeling and the components used in the latter correspond well to alterations in structural properties of the bulk matrix, while the electrochemical behavior can be additionally supported by morphological observations of the steel/cement paste interface.

(C) 2007 The Electrochemical Society. [DOI: 10.1149/1.2431318] All rights reserved.
\end{abstract}

Manuscript submitted June 26, 2006; revised manuscript received November 15, 2006. Available electronically January $18,2007$.

As is well known, corrosion in reinforced concrete is a great concern with respect to structure durability. Corrosion in concrete can take place when carbon dioxide has penetrated to the steel surface or when chloride content in the vicinity of the steel bars reaches certain threshold values. ${ }^{1}$ Consequently, breakdown of the passive layer, normally deposited on the steel surface in the concrete alkaline medium, is taking place. The assessment of the condition of reinforced structures in terms of time to initiate reinforcement corrosion, the level of damage, the performance of the system related to mechanical properties, evaluation of efficiency of protection techniques, etc. is always related to estimating corrosion rates, i.e., to determination of electrochemical parameters for the steel reinforcement in certain technical and environmental conditions. The electrochemical behavior of steel reinforcement has been extensively studied and outcomes are reported in literature. ${ }^{2-16}$ The intention of this work is to see how well different electrochemical techniques agree for reinforced cement-based materials rather than obtaining absolute quantitative parameters (such as corrosion rate for example) and, further, to correlate results with structural and morphological observations of the bulk matrix and the steel/cement paste interface, thus setting up a combination of techniques for the assessment of corrosion and protection in reinforced concrete.

\section{Applicability of Electrochemical Techniques to Reinforced Cement-Based Materials}

Different approaches hold for the performance of electrochemical (EC) measurements and their applicability to reinforced concrete, including possible errors in measuring the related corrosion parameters. ${ }^{73,13-20}$ A recent study ${ }^{21}$ presents comprehensive information on the application of EC techniques in investigating the corrosion of steel reinforcement, emphasizing the fact that all known techniques are applicable and useful for such systems and the inevitable errors in deriving quantitative results are mainly due to inaccurate performance of the techniques but not the techniques themselves. ${ }^{22-24}$ Generally, all EC techniques use simple models which might not always completely apply to all corrosion systems; therefore, the applicability of these techniques, especially in systems like reinforced cement-based materials, being relatively more complex, ${ }^{25}$ are subject to certain limitations, as already reported and

\footnotetext{
* Electrochemical Society Active Member

z E-mail: D.A.Koleva@TUDelft.nl
}

discussed in numerous works. ${ }^{13,16,17,19,20,26-30}$ Relevant to the application of electrochemical impedance spectroscopy (EIS), for example, problems occur in the shape of the response of reinforcing steel in concrete (mortar) in the Nyquist format, i.e., showing open and incomplete arcs when a capacitive behavior of the steel is observed or various semi- to depressed semicircles and further appearance of additional time constants due to corrosion and certain chemistry of the bulk material. ${ }^{2,4}$ Composing complex equivalent electrical circuits consisting of more time constants is not always a solution in the latter cases, as it is often difficult to attribute them to a good physical mode. ${ }^{3}$ For deriving the polarization (or charge transfer) resistance in EIS applications for reinforced concrete and mortar, the system response at the lowest frequency is generally considered for calculations, as reported in Ref. 15, 16, and 31-34, and is used in the present study as well. Some studies indicate that this response can also include redox reactions in the product layers. ${ }^{3,4}$ Additional complications and errors might appear in EIS measurements when high ac frequency is applied, such as in the case of inadequate polarization hold period, high solution resistance, etc. ${ }^{27}$ Despite this, the EIS technique remains a powerful tool for investigations in reinforced concrete and mortar systems, as it gives information for the interfacial phenomena and electrical and electrochemical properties of the materials involved, taking into consideration both the bulk cement-based matrix and the steel reinforcement. ${ }^{4,35}$

Relevant to dc measurements, like photoresist (PR), the above considerations for possible errors, applicability, and reliability hold as well, as reported elsewhere. ${ }^{2,3,11,6,36,37}$ In the case where corrosion rates have to be derived from PR measurements, complications and errors arise related to the following factors: ${ }^{17,18}$ not known Tafel slopes, lack of linearity of the polarization curve in the region of corrosion potential, lack of steady state, equilibrium potentials of anodic and cathodic reactions very close to the corrosion potential, etc. Although the drawbacks of the technique are well known, it is widely applicable for fast evaluation of electrochemical behavior (for example, deriving $R_{p}$ as in this study) for reinforced concrete or mortar systems. ${ }^{10,21,38,39^{9}}$ The arising errors can be minimized by establishing a correct sweep rate and waiting time during the measurements, e.g., potentiodynamic measurement using a $2.5-10 \mathrm{mV} / \mathrm{min}$ sweep rate $\operatorname{rat}^{17,21,27,29,40}$ gives reliable results.

The aim of this contribution is to investigate the applicability and reliability of a combination of techniques, which at first take into consideration both materials in a reinforced concrete system, i.e., the 


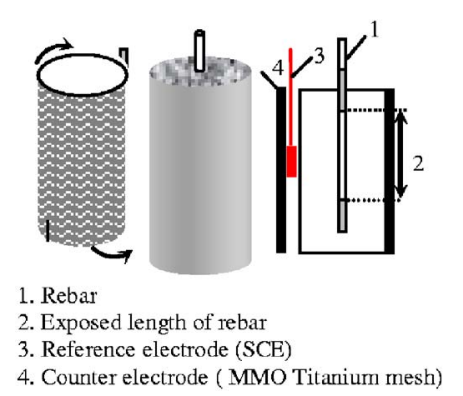

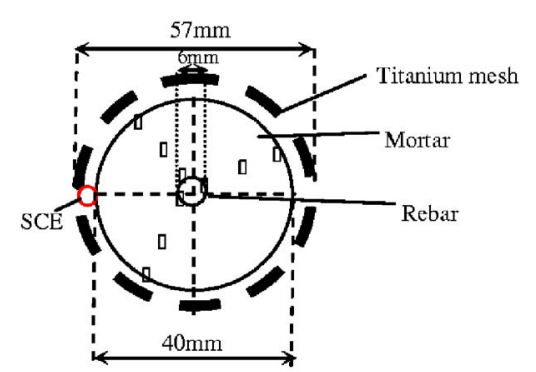

Figure 1. (Color online) Experimental setup and measurement configuration [the marked regions in the cross-sectional view (left) represent the locations for microstructural analysis]. bulk cement-based material and the steel surface. Further, we aim to investigate the relevant interfaces, like the interfacial transition zones (ITZs) in the bulk matrix (cement paste/aggregate) and the interface steel/cement-based material, both bearing significant alterations in conditions of chloride-induced corrosion. Finally, an attempt is made to correlate derived electrochemical behavior of the steel surface in corroding and noncorroding conditions with microstructural properties and, moreover, to visualize the relevant alterations of product layers using morphological investigations. To this end, the combination of techniques was intended to approach in a more fundamental way the understanding of corrosion of steel in concrete and, further, to enable verification of the efficiency of improved steel protection using electrochemical methods.

\section{Experimental}

Materials.- Mortar cylinders $(D=40 \mathrm{~mm}$ and $H=150 \mathrm{~mm})$ were cast according to standard procedures, using Ordinary Portland Cement CEM I 32.5 (cement-to-sand mixing proportion of 1:3 and water-to-cement ratio of 0.6). Ordinary construction steel bar [using FeB500HKN as-received steel $(d=6 \mathrm{~mm})$, i.e., no preliminary treatment] was centrally located (embedded length of $80 \mathrm{~mm}$ ) in all specimens. Group N (comprising specimens A and B) was cured in fog-room conditions [95\% relative humidity $\left.(\mathrm{RH}), 20^{\circ} \mathrm{C}\right]$ for 14 days and afterwards partially (1/3 of the height) submerged in $7 \%$ $\mathrm{NaCl}$ solution in lab-air conditions for 4 months. The poor mortar quality, the high water/cement ratio, and the relatively high $\mathrm{NaCl}$ concentration are designed to accelerate the corrosion process. A group denoted as R, using the same mortar mixture, reinforcement arrangement, casting procedures, and experimental conditions, but immersed in demineralized water, was investigated as a reference (control) specimen. Figure 1 depicts the experimental and measurements setup. The electrochemical measurements were performed in immersed conditions (ensuring conductivity of the medium) using mixed metal oxide (MMO) Ti mesh as counter electrode and external saturated calomel electrode (SCE) (Fig. 1) or, for verifications of results and monitoring, embedded $\mathrm{Mn} / \mathrm{MnO}_{2}$ as reference electrode. The chosen setup is found to be appropriate for measurements on steel in mortar (concrete) as previously used by the authors ${ }^{41}$ and reported also in Ref. 31.

Methods.- PR and EIS were performed at open-circuit potential (OCP) for all groups of specimens. For PR measurement, an external polarization in the range of $\pm 20 \mathrm{mV}$ vs OCP was used at a scan rate of $0.15 \mathrm{mV} / \mathrm{s}$; EIS was carried out in the frequency range of $50 \mathrm{kHz}$ to $10 \mathrm{mHz}$ by superimposing an ac voltage of $10 \mathrm{mV}$. The used equipment was EcoChemie Autolab-Potentiostat PGSTAT30, combined with FRA2 module, using general purpose electrochemical system (GPES) and frequency response analysis (FRA) interface.

Wet chemical analysis for determination of alkali and chloride concentrations was performed as well. The data obtained are not subject to the present contribution. Relevant to this study is the derived total chloride concentration, between 5.79 and $6 \mathrm{wt} \%$ per dry cement weight (using ASTMC1218 and ASTM C1152) in the immediate vicinity of the steel bar in the corroding specimens.
Scanning electron microscopy (SEM Philips XL30) combined with energy dispersive X-ray analysis (EDX) has been employed for visualization, morphological, and microstructure investigations. For measuring structural properties, a set of SEM section images of the specimens were obtained with backscattered electrons (BSE) mode, and the physical size of the reference region of each image is $226 \mu \mathrm{m}$ in length and $154 \mu \mathrm{m}$ in width, with a resolution of $0.317 \mu \mathrm{m} /$ pixel, corresponding to magnification of $500 \times$. The main outcome from a quantitative image analysis is deriving parameters such as porosity, pore-size distribution, and critical pore size, and further, based on mathematical morphology and stereology approaches, obtaining information for pore-distribution density, which corresponds in physical meanings to pore interconnectivity and permeability.

\section{Results and Discussion}

Potential mapping and polarization resistance.-In general, OCP readings for steel embedded in cement-based materials are widely used, ${ }^{30,42-44}$ aiming to determine the time-to-initiation of corrosion and evolution with time. In chloride-containing environments, corrosion initiation is related to passive-layer breakdown, and hence is due to exceeding certain threshold levels of chloride in the vicinity of the steel surface; consequently, potential mapping is used for determination of chloride thresholds as well. ${ }^{42}$ Although the potential readings can be significantly influenced by environmental conditions and the resistivity of the bulk material, as well as the degree of pore network saturation, ${ }^{45,46}$ they can give valuable qualitative information for the electrochemical behavior of the steel surface in such systems, and hence corrosion potential readings were used in the present study as supportive information. Figure 2 depicts the trends of OCP evolution with time for corroding (specimens A and $\mathrm{B}$, group $\mathrm{N}$ ) and reference (group R) specimens (up to 120 days of cement hydration).

As expected, the OCP for corroding specimens A and B (recorded in the potential intervals of -400 to $-650 \pm 40 \mathrm{mV}$ vs SCE)

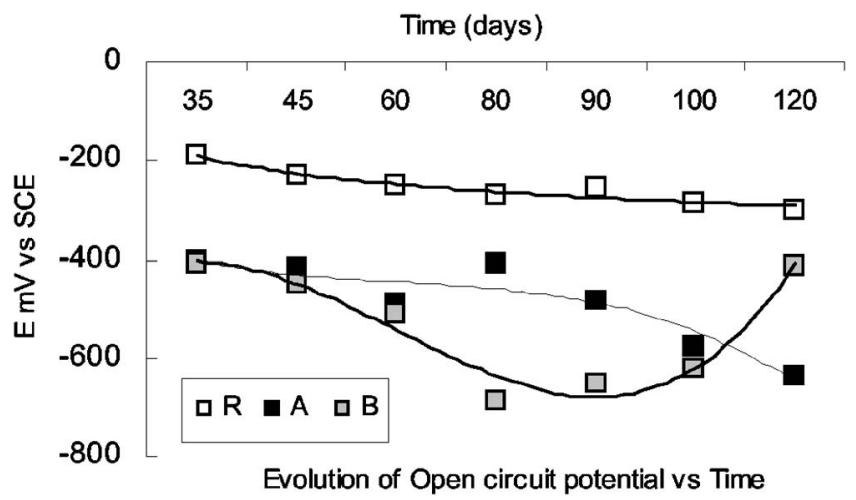

Figure 2. Evolution of OCP with time for noncorroding specimens (R) and corroding specimens A and B (group N). 


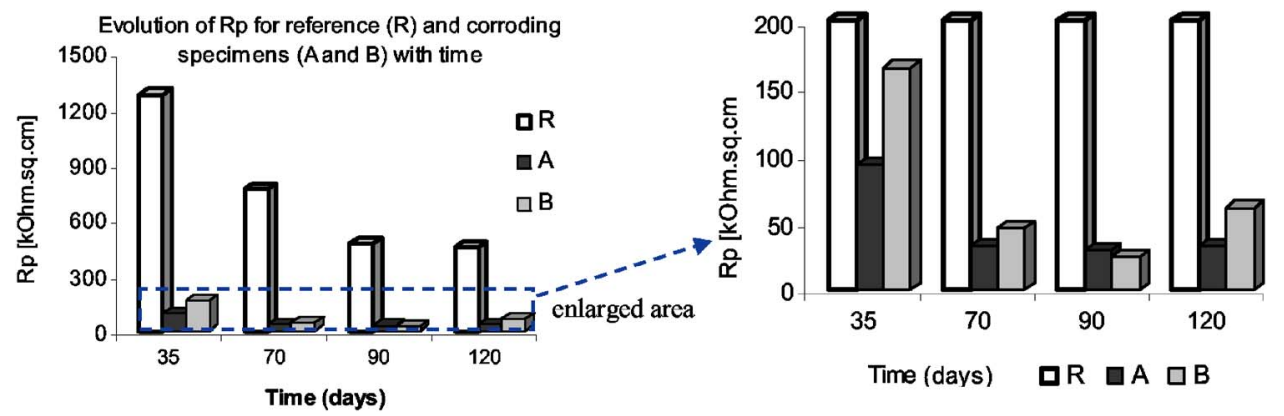

Figure 3. (Color online) Evolution of polarization resistance $\left(R_{p}\right)$ with time for noncorroding specimens (group R) and corroding specimens A and B (group N) (values are derived using PR method).

are beyond the threshold of passivity, which is generally accepted to be $-200 \pm 70 \mathrm{mV}$ vs SCE for reinforced mortar (concrete) systems. $42-44,47$

Because potential mapping is strongly influenced by the different phenomena in the bulk cementitious matrix and gives only qualitative information, quantification of the corrosion process can be obtained only by polarizing the steel surface, thus deriving parameters such as polarization resistance $\left(R_{p}\right)$, for example. In the present study, $R_{p}$ was derived from PR and EIS, taking into considerations all requirements and aspects related to reliable calculation and performance of the measurements. $4,16,40,48$

Figure 3 depicts the recorded $R_{p}$ values from PR measurements, the $R_{p}$ values for noncorroding specimens (group $\mathrm{R}$ ) being, as expected, about 1 order of magnitude higher than corroding specimens (group $\mathrm{N}$ ) at the end of the test. A slight deviation from the passive threshold (potential of $-250 \mathrm{mV}$ vs SCE) was recorded for the reference (noncorroding) specimens, reflected by a drop of $R_{p}$ values (Fig. 3) between 35 and 60 days of age. Similar behavior and observations were recorded in previous studies as well. ${ }^{41}$ Calcium carbonate and iron hydroxy-carbonates were detected in small amounts on the steel surfaces (Fig. 4). The carbonate compounds are formed most likely in the process of initial hardening of the mortar mixture and the presence of $\mathrm{CO}_{2}$ in the mixing water or due to very slow penetration of atmospheric $\mathrm{CO}_{2}$ through the mortar cover. This penetration is additionally promoted by the poor quality of the investigated mortar (w/c ratio of 0.6 , large air voids), small dimension of the sample, small cover depth, and high degree of structural heterogeneity of the system. The X-ray diffraction (XRD) observations
(Fig. 4) support the above statements, but a uniform carbonation front cannot be expected in this case. These observations, along with the fundamental behavior of steel in alkaline solution, explain the shift of the $R_{p}$ for noncorroding specimens to lower values but still considerably higher compared to corroding specimens (Fig. 3 and Table I).

Electrochemical impedance measurements. - A schematic presentation of the systems under study is presented on Fig. 5. At least three interface regions should be considered in the interpretation of the impedance response (Fig. 5 left), i.e., the interface of electrolyte and concrete bulk (incorporating concrete cover) (region 1), the inner bulk matrix (region 2), and the steel/cement paste interface (region 3).

The equivalent circuit used in the present study (Fig. 5 right) comprises two time constants in series with the electrolyte resistance. The elements of the equivalent circuit are suggested to have physical meaning as follows: $R_{\mathrm{eI}+b}$ is the electrolyte $(7 \% \mathrm{NaCl}$ in the case of corroding groups or demineralized water in the case of the reference group), including contribution of the mortar overall bulk resistance, the first time constant $\left(R_{\mathrm{pn}}\right.$ and $\left.\mathrm{CPE}_{\mathrm{pn}}\right)$ is attributed to the properties of the cementituous matrix in terms of pore network, and the second time constant $\left(R_{\mathrm{ct}}\right.$ and $\left.\mathrm{CPE}_{\mathrm{dl}}\right)$ deals with the electrochemical reaction on the steel surface. The experimental impedance response in Nyquist and Bode formats for all groups is presented in Fig. 6-8. Summarized data for the best-fit parameters are presented in Table I.

The shape of the experimental curves for all specimens reflects

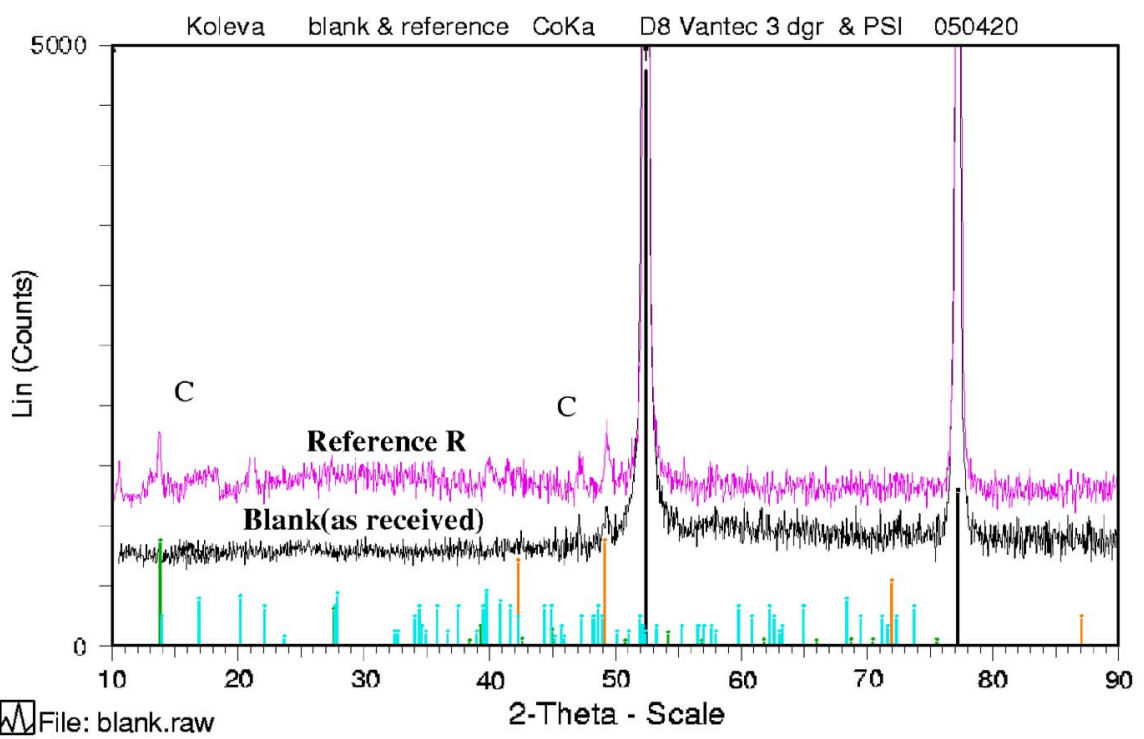

MFile: referencepsi_050420.raw

口06-0696 ( $\left.{ }^{*}\right)$ - Iron, syn - Fe

06-0615 (l) - Wustite, syn - FeO
46-0098 (I) - Iron Carbonate Hydroxide - Fe6(OH)12(CO3)

33-0650 (I) - Iron Carbonate Hydroxide - $\mathrm{Fe} 2(\mathrm{OH}) 2 \mathrm{CO} 3$
Figure 4. (Color online) XRD (using $\mathrm{Co} \mathrm{K} \alpha$ radiation) patterns for the steel surface in reinforced mortars from reference group (Ref. 41) and blank sample (as-received) steel. The XRD pattern evidences the presence of iron and calcium carbonates due to $\mathrm{CO}_{2}$ penetration to the steel surface. 


\begin{tabular}{|c|c|c|c|c|c|c|c|}
\hline Age (days) & $R_{\mathrm{el}+b}(\Omega)$ & $Y_{0}, Q_{\mathrm{prp}} 1(\Omega)$ & $n$ & $R_{\mathrm{pn}}(\Omega)$ & $R_{\mathrm{cl}}\left(k \Omega \mathrm{cm}^{2}\right)$ & $Y_{0}, Q_{\mathrm{d}} 1(\Omega)$ & $n$ \\
\hline \multicolumn{8}{|l|}{ Gr.R } \\
\hline 35 & 400 & $5.44 \times 10^{-9}$ & 0.6596 & 215 & 1298 & $3.20 \times 10^{-4}$ & 0.8686 \\
\hline 70 & 768 & $2.62 \times 10^{-9}$ & 0.6607 & 435 & 787 & $3.15 \times 10^{-4}$ & 0.8547 \\
\hline 90 & 881 & $1.70 \times 10^{-9}$ & 0.6302 & 512 & 450 & $2.65 \times 10^{-4}$ & 0.8417 \\
\hline 120 & 1397 & $9.87 \times 10^{-10}$ & 0.6241 & 755 & 420 & $3.07 \times 10^{-4}$ & 0.8532 \\
\hline \multicolumn{8}{|c|}{ Gr N, specimen A } \\
\hline 35 & 202 & $4.90 \times 10^{-7}$ & 0.6232 & 22 & 171 & $3.86 \times 10^{-4}$ & 0.7631 \\
\hline 70 & 208 & $8.35 \times 10^{-10}$ & 0.3643 & 27 & 36 & $3.53 \times 10^{-4}$ & 0.7824 \\
\hline 90 & 230 & $7.56 \times 10^{-10}$ & 0.4213 & 38 & 35 & $3.96 \times 10^{-4}$ & 0.8131 \\
\hline 120 & 264 & $6.93 \times 10^{-6}$ & 0.5744 & 54 & 30 & $2.76 \times 10^{-4}$ & 0.7501 \\
\hline \multicolumn{8}{|c|}{ Gr N, specimen B } \\
\hline 35 & 207 & $1.38 \times 10^{-7}$ & 0.5853 & 23 & 230 & $3.49 \times 10^{-4}$ & 0.7848 \\
\hline 70 & 216 & $2.82 \times 10^{-9}$ & 0.4662 & 36 & 44 & $3.69 \times 10^{-4}$ & 0.7631 \\
\hline 90 & 224 & $1.56 \times 10^{-10}$ & 0.4103 & 63 & 59 & $2.86 \times 10^{-4}$ & 0.6343 \\
\hline 120 & 307 & $1.27 \times 10^{-7}$ & 0.4709 & 74 & 81 & $1.40 \times 10^{-4}$ & 0.6871 \\
\hline
\end{tabular}

the typical response of reinforcing steel in the alkaline medium of cement paste and in conditions of chloride present at the steel/paste interface, as reported also in Ref. 21, 31, and 32.

Because the specimen geometry is equal for all groups and specimens, the diagrams apply for the total electrode, without conversion for surface area. The same holds for the fit parameters in Table I, except the charge transfer resistance $\left(R_{\mathrm{ct}}\right)$, calculated in $\mathrm{k} \Omega \mathrm{cm}^{2}$ (electrode surface area is $16 \mathrm{~cm}^{2}$ ).

The replacement of pure capacitance $(\mathrm{C})$ with constant phase element (CPE) in the equivalent circuits (Fig. 5) is widely accepted for systems as in this study, ${ }^{2,5,16,49}$ being denoted to inhomogeneities at different levels, i.e., steel surface roughness, bulk matrix heterogeneity, etc. The CPE is an empirical mathematical description of the observed impedance response and is defined by Ref. 50 as: $Z=(j \omega)^{-n} / Y_{0}$, being further quantified by the parameters $Y_{0}$ and $n$ (CPE constant and CPE factor, respectively).

At low frequencies $(0.01 \mathrm{~Hz})$ close to capacitive behavior was observed for group R, indicating a situation of passivity (Fig. 6), in contrast to the incline to the real-axis semicircles for the corroding group N, specimens A and B (Fig. 7 and 8), reaching a shape of a semidepressed circle in the case of group A (Fig. 7). The response for group $\mathrm{N}$ reflects the evolution of corrosion with time, also evidenced by the more significant phase-angle drop for these specimens, compared to the reference group R (Bode plots in Fig. 6-8). The impedance response in the low-frequency domain was used for deriving the charge-transfer resistance of the steel bars. ${ }^{15,16,31-34}$ The recorded $R_{\mathrm{ct}}$ for group $\mathrm{R}$ was at least 1 order of magnitude higher than the $R_{\mathrm{ct}}$ for group $\mathrm{N}$ (Table I).

The high-frequency arcs (incorporated plots of enlarged areaupper right of the Nyquist plots for each group, Fig. 6b, 7b, and 8b) and the response evolution with time suggest that $R_{\mathrm{el}+b}$ is the electrolyte resistance, including contribution of the mortar bulk resistance, as the derived values increase with time due to cement hydration (cement hydration modifies the microstructure of the bulk matrix as hydration products gradually fill in the available space in the cement paste). The derived values for $R_{\mathrm{el}+b}$ for the reference group are in the range of 400-1390 $\Omega$ (from 35 to 120 days of age) and about $200-300 \Omega$ for the corroding groups (Table I), which is consistent with observations in similar research, ${ }^{3}$ reporting resistance of $900 \Omega$ for mortar free of chloride and $450 \Omega$ for mortar containing 1\% chloride (about $6 \%$ total chloride per dry cement weight was found at the steel/cement paste interface, hence lower resistivity was observed for the relevant specimens in this study).

In modeling the steel/cement paste interface, several researchers ${ }^{13,16,51}$ have proposed the equivalent circuits to include elements for diffusion in addition to the CPE, coupled with the charge transfer $\left(R_{\mathrm{ct}}\right)$. Including diffusion elements normally explains low-frequency tails which could appear in some impedance diagrams ${ }^{2}$ however, such response was not observed in the present study. The EIS measurements were performed up to $10 \mathrm{mHz}$ as lowest frequency for both corroding and noncorroding groups, hence the charge process of CPE predominates in the response and no diffusion effects (which are at frequency lower than $1 \mathrm{mHz}$ for passive and lower than $5 \mathrm{mHz}$ for active state ${ }^{16}$ ) were recorded. The proposed circuit (Fig. 5) gives generally good-fitting results. We did not include additional components, taking into consideration the time of exposure and test conditions of only 4 months.

Looking at the equivalent circuit (Fig. 5) and the fit parameters (Table I), the first time constant (for all groups) is definitely related to the pore network of the bulk material, as the power of CPE is mostly in the range of $0.4-0.6$, and pseudo capacitance values are very low $\left(Y_{o}\right.$ in the range of $1.3 \times 10^{-7}$ to $\left.9.8 \times 10^{-10}\right)$, and hence cannot be denoted to the electrical double layer on the steel surface or to redox reactions. ${ }^{52}$ The second time constant is related to the charge-transfer resistance and double-layer capacitance at the steel surface, as the CPE power in the range of $0.69-0.86$ is related to the electrochemical reaction, and the pseudo capacitance is stable with time for the reference group and increases for the corroding groups, which is consistent with the drop of the derived $R_{\mathrm{ct}}$ of the latter two.

Obviously, an equivalent circuit with a single capacitor is not in
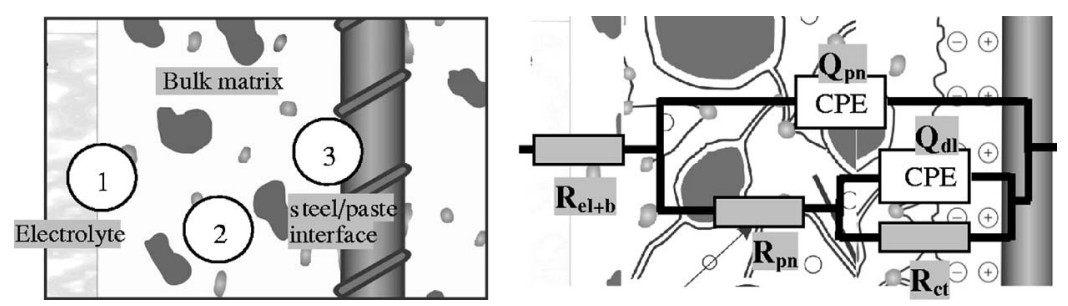

Figure 5. Schematic model of involved interfaces (left) and corresponding equivalent electrical circuit, used to fit the experimental EIS data (right) for the specimens under study. 


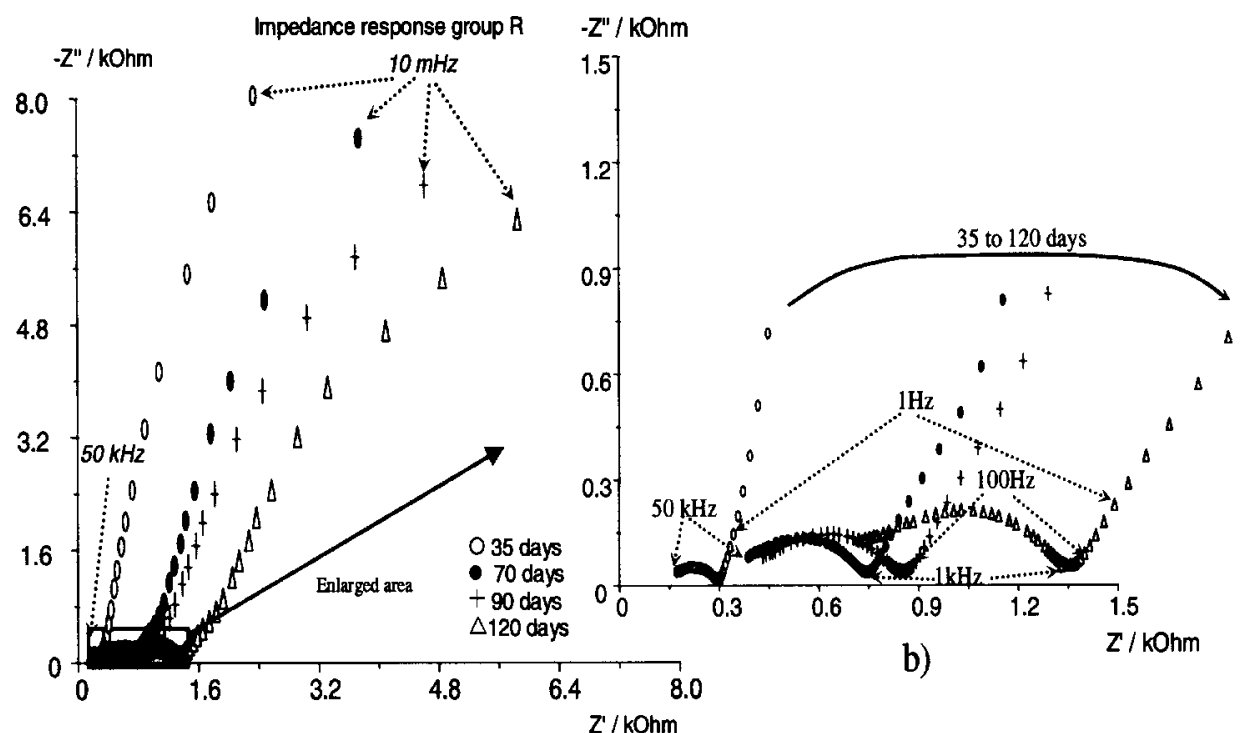

a)

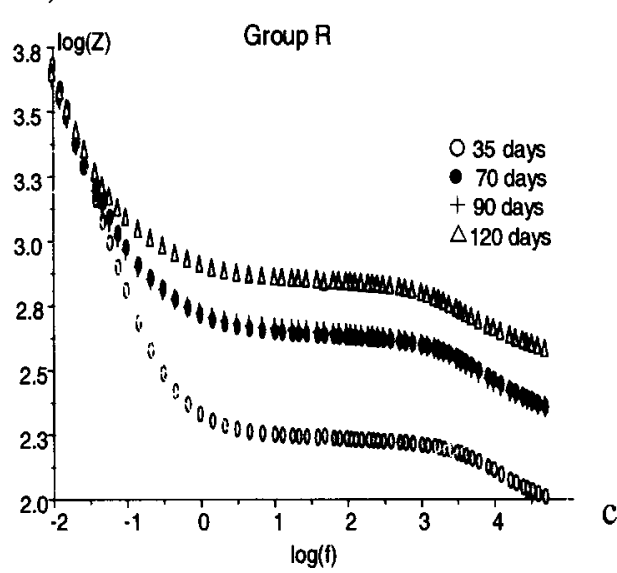

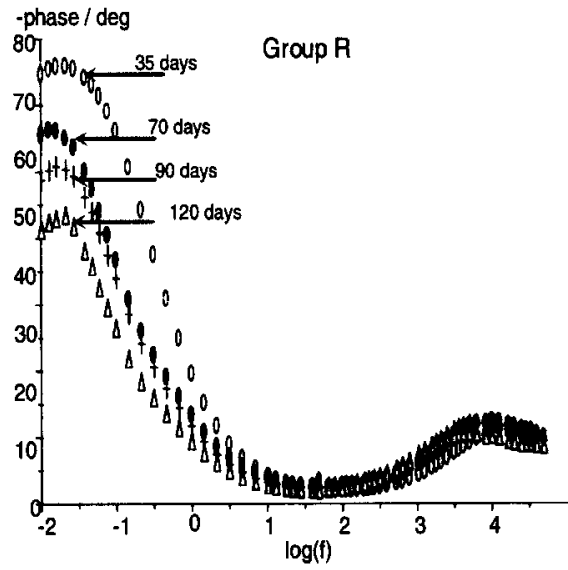

Figure 6. EIS response for noncorroding specimens (group R) for the time domain 35-120 days of age: (a) Nyquist format, (b) enlarged area of high-frequency response, and (c) Bode plots. harmony with the response of all specimens. However, it is questionable if phase shifts originating from phenomena very different from real capacitance, especially in such systems, can be modelled with complicated electrical circuits. ${ }^{3}$ Hence, the proposed relatively simplified equivalent circuit is believed to be satisfactory for evaluation of the system parameters, where the components have clear physical meaning. This consideration is supported by the values obtained from the fitting procedures (Table I), which correspond well to values reported in similar research ${ }^{3,7,31,52-54}$ and are evidenced by an acceptable error (see Fig. 9). The sine shape indicates that obviously the equivalent circuit can be further improved; however, more complicated circuits are not addressed in this paper. The relative error in the frequency domain $100-0.01 \mathrm{~Hz}$ (corresponding to the frequency region for the calculation of $R_{\mathrm{ct}}$ ) is almost zero, hence the determined values for charge-transfer resistance can be considered as reliable. Moreover, the derived values for $R_{\mathrm{ct}}$ are consistent with the derived $R_{p}$ values from PR method (see Fig. 10).

Table I comprises the best-fit values for the rest of the components from the equivalent circuits, including pore-network resistance and charge-transfer resistance, which are further discussed in correlation with microstructural properties of the bulk material.

Microstructural analysis. - The electrolytic path in reinforced mortar and concrete systems is dependent on the kinetics of aggressive ion-transport mechanisms which are affected by pore-size distribution and pore connectivity. Porosity and ionic conductivity are related to main physicochemical processes, which affect the material properties. Hence, pore structure is highly relevant to the electrical properties of materials and consequently influences the electrochemical phenomena in systems, as in the present study.

The critical pore size can be conceived as the diameter of the pore that completes the first interconnected pore pathway in a network, developed by a procedure of sequentially adding pores of diminishing size to this network; the critical pore size can be associated with the inflection point of a cumulative pore-size distribution curve. ${ }^{55}$ The critical pore size is a unique transport-length scale of major significance for permeability properties. In this study, using a refined form of the Katz and Thompson equation, ${ }^{56}$ the cumulative pore-size distribution is obtained from the so-called openingdistribution analysis, performed on section images of the concrete specimens.

For predicting the permeability of porous materials, Eq. 1, which is the Katz-Thompson equation, is generally used

$$
k=1 / 226 \cdot l_{c}^{2} \cdot \vartheta / \vartheta_{0}
$$

where $l_{c}$ is the critical pore diameter, $\vartheta$ is the electrical conductivity of the sample, and $\vartheta_{o}$ is the electrical conductivity of the pore solution. Further, according to the Carman-Kozeny model, ${ }^{57}$ the permeability of cement paste can be predicted on the basis of geometrical properties of pore space, using

$$
k=-p\left(V_{\text {pore }} / S_{\text {pore }}\right)^{2} / 2 \beta
$$

where $\rho$ is the porosity, $V_{\text {pore }}$ and $S_{\text {pore }}$ are the volume and surface area of pore space, and $\beta$ is the tortuosity of the transport route in the cement. An improvement and refinement of the Katz-Thompson equation is necessary, however, for the purpose of predicting con- 


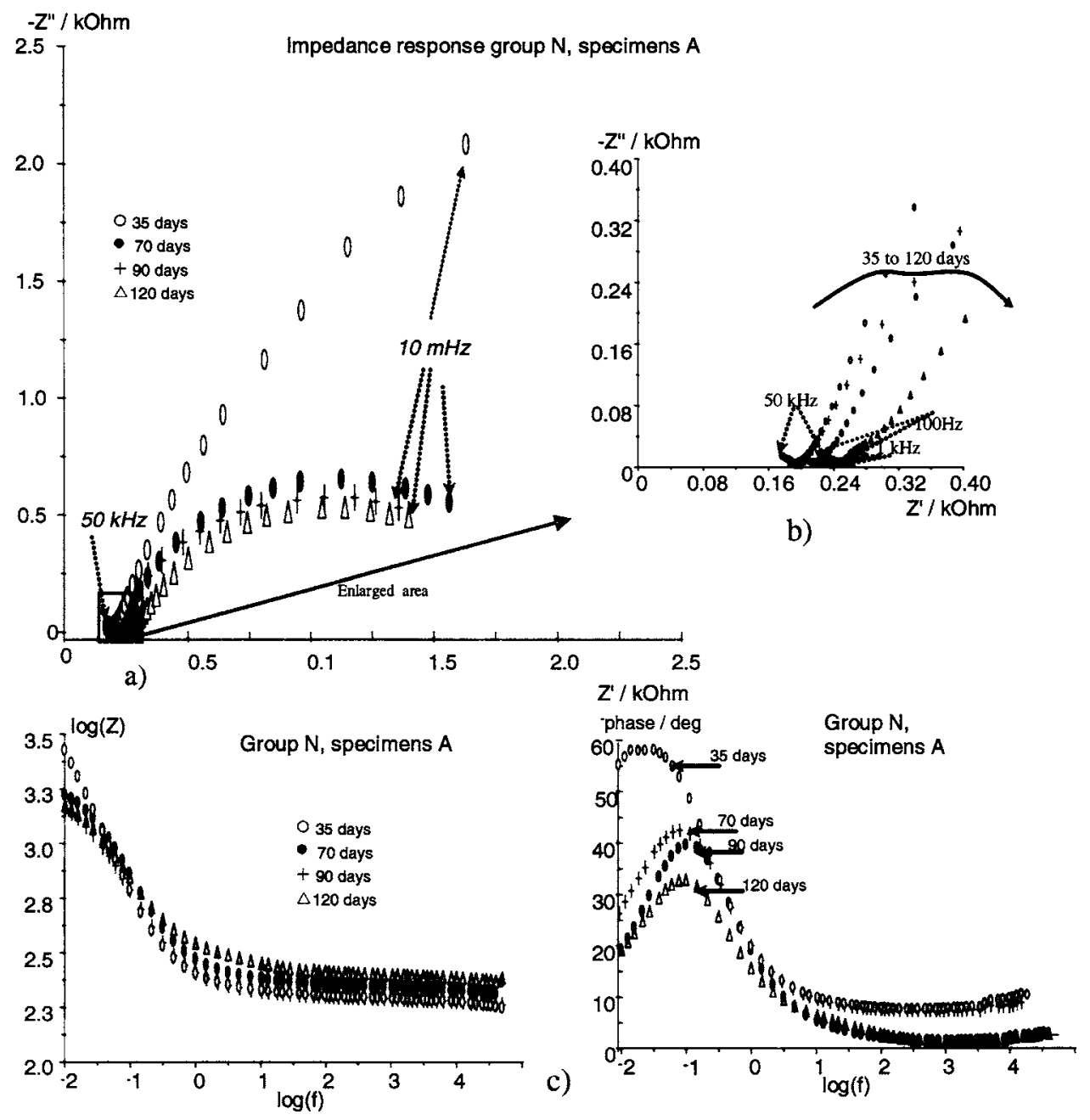

Figure 7. EIS response for corroding specimens A (group $\mathrm{N}$ ) for the time domain 35-120 days of age: (a) Nyquist format, (b) enlarged area of high-frequency response, and (c) Bode plots. crete permeability. The modifications are based on structural information, derived from section image analysis, incorporating 3D parameters or the so-called pore-distribution density (PDD), employed in this study.

PDD is a three-dimensional structural parameter, derived from the skeleton length of pore features, observed on two-dimensional section images. It is found to have a high relation to pore connectivity, water permeability, and ion transport, ${ }^{55}$ and consequently is related to the corrosion phenomena in the vicinity of the steel surface. It is impossible to assess the 3D distribution density directly from image analysis of $2 \mathrm{D}$ sections. An alternative is to determine the $2 \mathrm{D}$ distribution density from specimen sections and to calculate the $3 \mathrm{D}$ distribution density on the basis of stereological theory. The 2D distribution density $\Gamma_{2 \mathrm{D}}$ of pore space in an image with area $A$ encompassing $N$ skeleton segments of length $l_{i}$ is defined by

$$
\Gamma_{2 \mathrm{D}}=\sum_{i=1}^{N} l_{i}^{2} / A
$$

For application to transport studies, the parameter $l_{i}$ has to be correlated with the length of a skeleton segment in $3 \mathrm{D}$ distribution, denoted as $l_{\mathrm{ac}}$ and given by Eq. 4

$$
l_{i}=l_{\mathrm{act}} \int_{0}^{\pi / 2} \sin \theta^{2} d \theta=\pi / 4 l_{\mathrm{act}} \text { or } l_{\mathrm{act}}=4 / \pi l_{i}
$$

Equation 4 yields the actual length of a skeleton segment in 3D space. Further, the relationship between 2D and 3D PDD is provided by stereological theory, ${ }^{58}$ using

$$
\Gamma_{3 \mathrm{D}}=2 / \pi \cdot N_{A} l_{\text {act }}^{2}=2 / \pi N_{A}(4 / \pi)^{2} l_{i}^{2}=32 / \pi^{3} \Gamma_{2 \mathrm{D}}
$$

where $N_{A}$ represents the number of skeleton segments per unit area of the test image in 2D (i.e., the 2D PDD is converted to 3D).

Finally Eq. 6, used in this study, is the refined form of the KatzThompson equation

$$
\begin{aligned}
k= & l_{c}^{2.1} / 27800 . \exp \left(1.7 \Gamma_{3 \mathrm{D}}\right)\left[0.001+0.07 p^{2}+H\left(p-p_{c}\right)\right. \\
& \left.\times\left(p-p_{c}\right)^{1.5}\right]
\end{aligned}
$$

where $p_{c}$ is the critical value of capillary porosity for percolation and $H\left(p-p_{c}\right)$ equals 1 if $p>p_{c}$ or equals 0 otherwise. Detailed information for the open-distribution technique, PDD, and the stereological approaches can be found in Ref. 59.

The structure parameters in the present study were derived on the basis of microstructural investigation in the radial direction around the steel bar (see Fig. 1); investigation of similar test series are already reported by the present authors in Ref. 60 and 61. Generally, the interfacial zone at the steel surface exhibits a high connectivity and a coarser pore structure than the bulk matrix. Figure 11 clearly shows that for the reference group $\mathrm{R}$, the interfacial porosity is the highest, and the bulk and edge porosity are similar to the corroding groups. The pore connectivity of group $\mathrm{R}$ is lower than corroding group $\mathrm{N}$, specimens $\mathrm{A}$, and almost equal to specimens $\mathrm{B}$. The phenomena are attributed to the formation of the so-called Hedley grains, which are hollow hydrate shells surrounded by a thin shell of calcium-silica-hydrate $(\mathrm{C}-\mathrm{S}-\mathrm{H})$. The reasons for this phenomenon are not well understood, but it is believed that the formation of possibly amorphous hydration product on the surface of the cement 


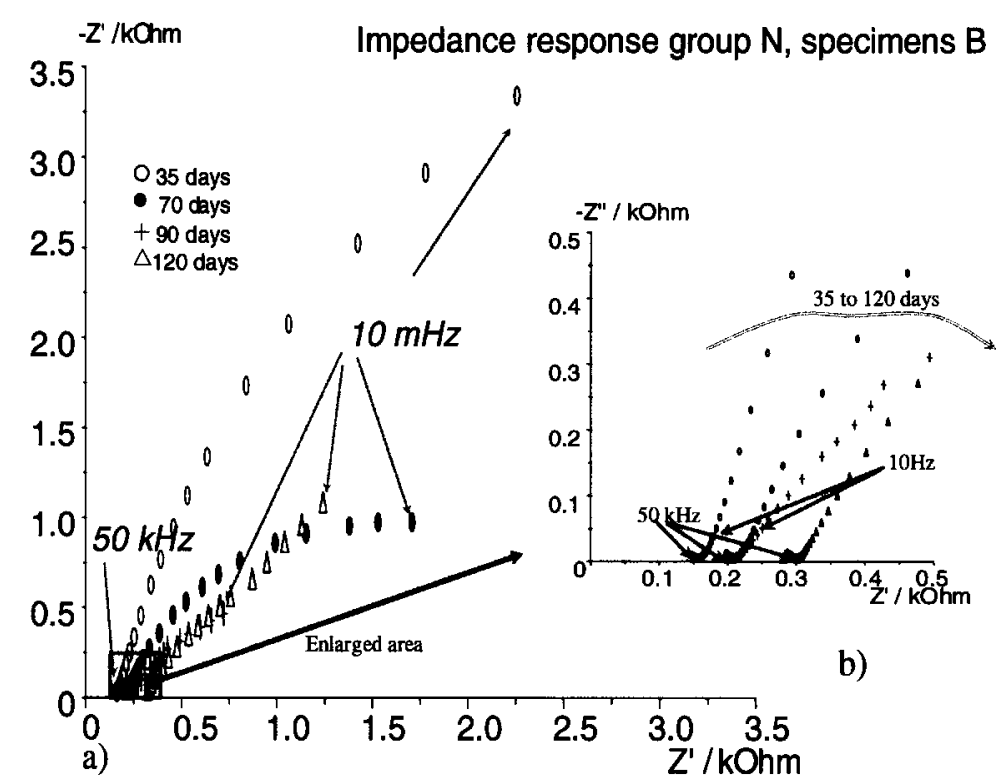

c)

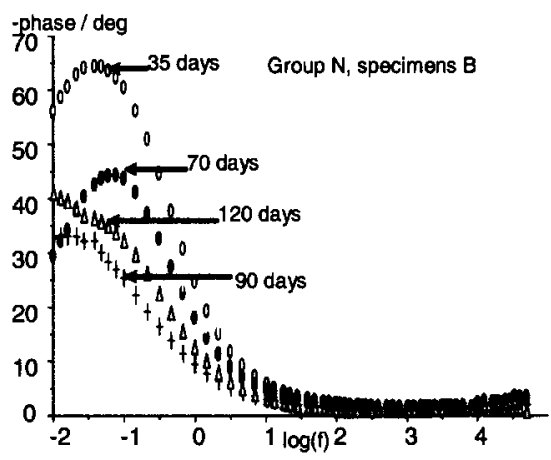

Figure 8. EIS response for corroding specimens B (group N) for the time domain 35-120 days of age: (a) Nyquist format, (b) enlarged area of high-frequency response, and (c) Bode plots. grains might inhibit the precipitation of $\mathrm{C}-\mathrm{S}-\mathrm{H}$ on the grain surface and lead to the formation of the separated shells, ${ }^{62}$ which contribute to the total porosity but do not affect the structure permeability and connectivity.

Hence, ion and water transport cannot be determined by only one parameter alone but should be considered as a function of a combination of structural parameters. These parameters bare alterations in conditions of chloride ingress, chloride binding, and corrosion at the steel/paste interface, which is the main reason for the different electrochemical behavior of the steel surface in specimens of group $\mathrm{N}$ (specimens A and B), being otherwise completely identical in mixture, setup, and specimens geometry. This consideration is evidenced by the significant difference in pore-structure parameters of specimens A and B at the end of the testing period (Fig. 11) and supports the experimental results from all electrochemical methods.

Microstructural and morphological observations on the steel/ paste interface.-Chlorides are found to be either free (Fig. 12 left, depicting free chloride in the form of $\mathrm{NaCl}$ in the vicinity of the steel surface) or physically and chemically bound. The chemical binding of chloride ions is a process of incorporation into the lattice of crystalline hydration products in the form of $3 \mathrm{CaO} \cdot \mathrm{Al}_{2} \mathrm{O}_{3} \cdot 3 \mathrm{CaCl}_{2} \cdot 10 \mathrm{H}_{2} \mathrm{O}$ (Friedel's salt) (Fig. 12 right).

Chloride binding is beneficial as far as corrosion processes are concerned, as the amount of free chloride in the pore solution is decreasing, although as reported in Ref. 63, bound chloride presents risks for corrosion initiation as well. In conditions of chloride ingress, the release of $\mathrm{NaOH}$ during Friedel's salt formation lead to an increase in the $\mathrm{pH}$ of the pore solution. The increased $\mathrm{pH}$ accelerates the hydration process and consequently modifies the pore structure towards a finer pore-size distribution, as demonstrated by the porestructure analysis and also reported in other studies. ${ }^{64-66}$ Iontransport mechanisms (particularly chloride ions) and physicochemical alterations in such conditions significantly influence the electrochemical processes taking place on the steel surface. Moreover, as evidenced by the present investigation, they all depend on the bulk-matrix structural modifications and consequently determine the corrosion behavior of the steel surface to a significant extent.

Morphological investigation in terms of corrosion product evaluation and quantitative determination techniques were employed on cross sections of the steel/mortar interface and on a longitudinal
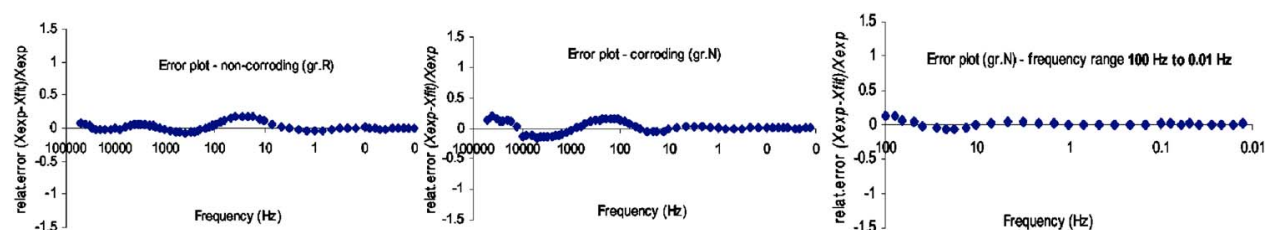

Figure 9. (Color online) Error plots for specimen group $\mathrm{R}$ (left), group $\mathrm{N}$ (middle), and group $\mathrm{N}$ in the frequency domain $100-0.01 \mathrm{~Hz}$. (The error was estimated according to $R_{\text {elerr }}=X_{\text {exp }}$ $\left.-X_{\mathrm{fit}} / X_{\mathrm{exp}}\right)$. 


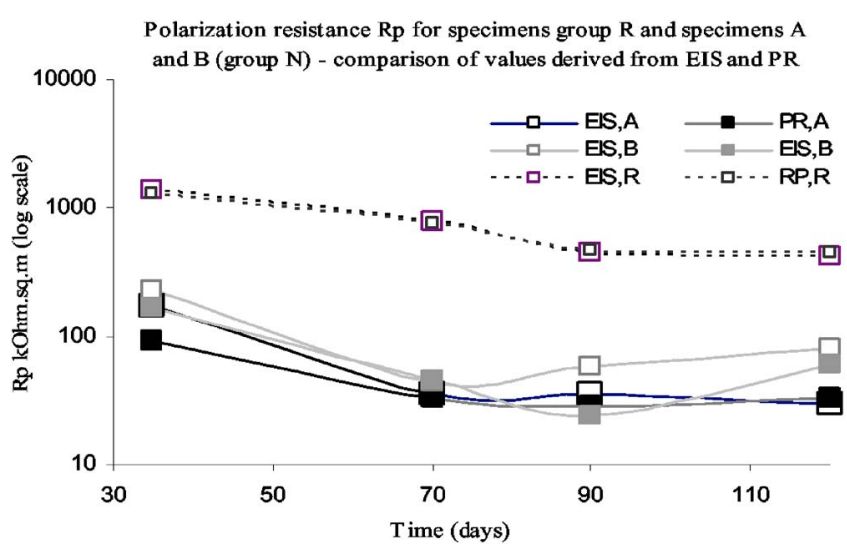

Figure 10. (Color online) Comparison of $R_{p}$ values for noncorroding specimens (group R) and corroding specimens A and B (group N), derived from PR and EIS methods.

section of the steel surface. Direct visualization of formed corrosion products and chemical composition around the steel surface are shown in Fig. 13-16.
Figure 13 depicts the intact steel/cement paste interface in the reference (noncorroding) specimen, evidenced by the EDX mapping (Fig. 13 right), revealing the passive state of the reinforcement. The steel surface was mainly covered by a calcium-rich layer in the form of calcium oxide/hydroxide plates, (Fig. 14 left) and $\mathrm{C}-\mathrm{S}-\mathrm{H}$ gels from the cement paste (Fig. 14 right).

In contrast, the visual observation and EDX mapping (Fig. 15) for the corroding specimens reveals the accumulation of iron oxides and/or iron oxy-chlorides at a distance of $100 \mu \mathrm{m}$ away from the steel bars. The accumulation of corrosion products leads to a series of microstructural changes in the systems under study. The detected iron oxides/oxyhydroxides $(\mathrm{FeOOH})$ may vary in chemical composition and present different morphologies, according to which they can be categorized as geothite $(\alpha-\mathrm{FeOOH})$, lepidocrocite $(\gamma-\mathrm{FeOOH})$, or akaganeite $\left[\mathrm{Fe}^{3+}(\mathrm{O}, \mathrm{OH}, \mathrm{Cl})\right]$.

The various morphologies and chemical compositions of the corrosion products determine the different extent of volume expansion and penetration in the cement paste, filling in pores or voids (e.g., akaganeite typically grows in air voids or in cracks) and cause further concrete cracking. More information on corrosion product formation and distribution in different technical conditions has already been reported by the authors in Ref. 41 .

EDX analysis of the corrosion products reveals similar chemical composition, mainly iron oxides and iron oxychloride complexes,
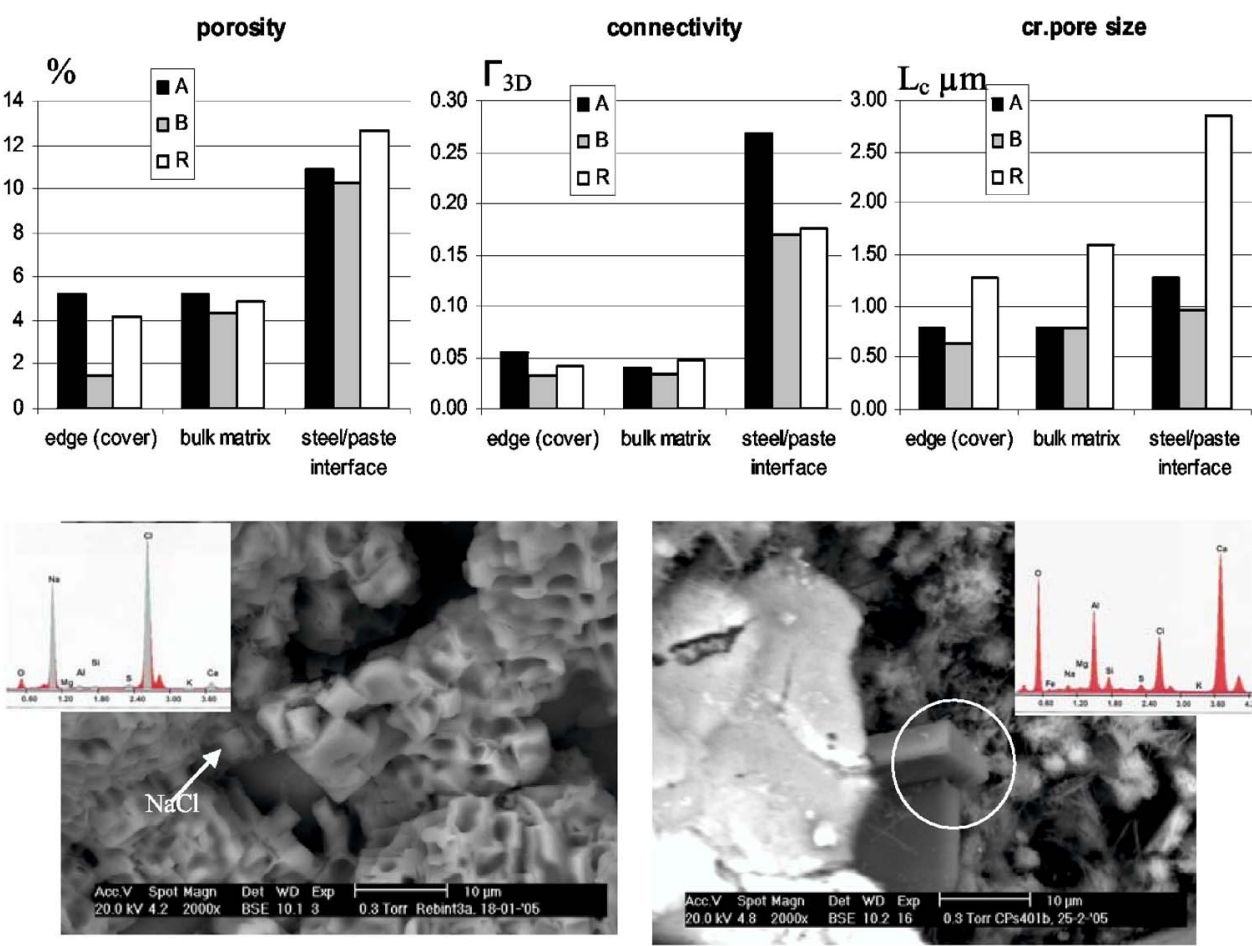

Figure 11. Structural parameters: (a) porosity, (b) connectivity, and (c) critical pore size, derived for corroding specimens $\mathrm{A}$ and $\mathrm{B}$ (group $\mathrm{N}$ ) and noncorroding specimens (group R) at the interface, bulk, and edge regions (regions schematically presented in Fig. 1).

Figure 12. (Color online) Morphological observation at the steel/mortar interface of corroding specimen B (group N): (left) free $\mathrm{NaCl}$, (circled) bound chlorideFriedel's salt, and (right) Ca-rich layers (white layer on the left part of the micrograph).
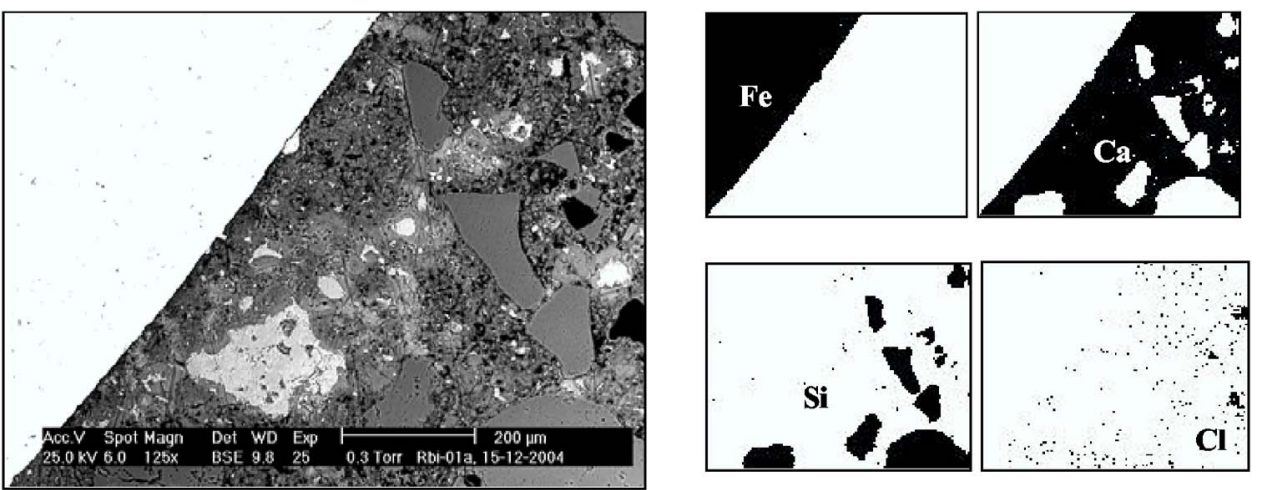

Figure 13. (Left) Cross section of steel/ mortar interface of the reference specimen, magnification $125 \times$ and (right) EDX multielement mapping, revealing the calcium-rich layer in the steel/cementpaste interface 


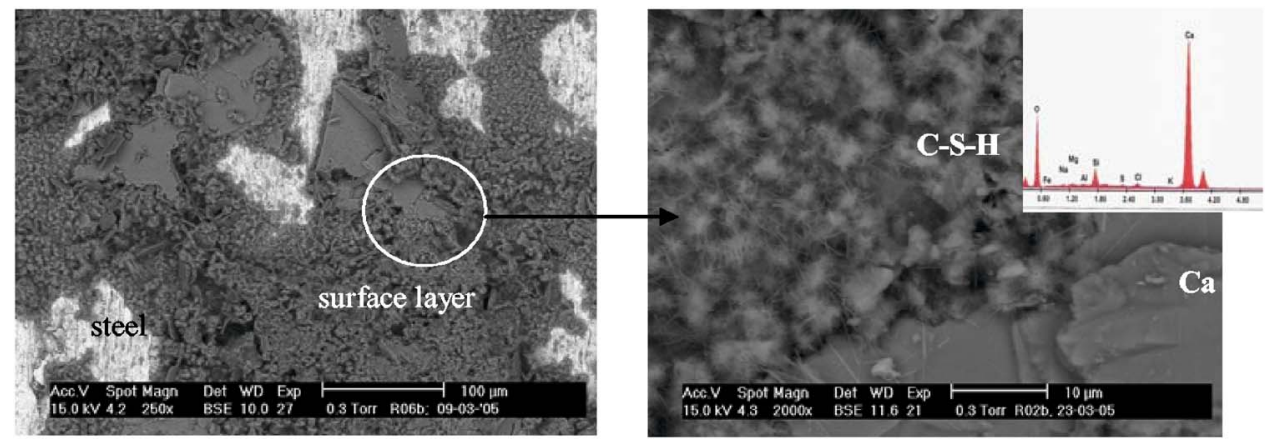

Figure 14. (Color online) Longitudinal section (steel surface), showing (left) distribution of calcium-enriched product layer (white regions are the steel surface) and (right) morphology and EDAX analysis of the circled zone in the noncorroding specimens (group R).

despite the different morphology (Fig. 16). This is attributed to the different mass ratio of iron and chloride ions. When the $\mathrm{Fe} / \mathrm{Cl}$ ratio of atomic \% is in the range of 3-3.5, the complexes present a general lamellar shape. In contrast, at a much higher ratio of $6.5-7$, a globular shape is observed. The former type is expected to be responsible for volumetric expansion rather than the delicate, globular, and whiskery minerals.

\section{Correlation of Electrochemical Behavior and Microstructural Properties}

As previously discussed, the high-frequency impedance response in EIS measurements is attributed to bulk-matrix properties. If the resistance values (Table I) are recalculated to give resistivity, using the geometry of the cell (equal for all conditions), the derived values, ranging between 52 and $180 \Omega \mathrm{m}$ for the reference and between 26 and $40 \Omega \mathrm{m}$ for the corroding groups, are completely consistent with preliminary research of the present authors on electrical properties of plain mortar, using the same mixture, ${ }^{60}$ where values of $30-50 \Omega \mathrm{m}$ were derived for 60 days of age, using 2- and 4-pin ac methods. The difference for corroding specimens is attributed to the additional phenomena of corrosion, volume expansion, and microcracking, along with the higher chloride concentration at a later stage for the specimens in the present study. Hence, a relatively proper estimation of bulk-matrix resistance can be derived from EIS measurements, starting at $50 \mathrm{kHz}$ as highest frequency, taking into consideration the experimental conditions, mortar mixture, and age.

Figure 17 depicts the evolution of the bulk-matrix resistivity and the pore-network resistivity in $\Omega \mathrm{m}$ for group R (left) and group $\mathrm{N}$, specimens A and B (right), derived from the EIS data and in particular the resistance $R_{\mathrm{el}+b}$ (including electrolyte) and the resistance $R_{\mathrm{pn}}$. It is evident that the noncorroding group (R) exhibits higher values of bulk- and pore-network resistivity, increasing with time, despite the more open pore structure and lower rate of cement hydration. In contrast, the corroding specimens A and B are characterized by much lower bulk- and pore-network resistivity values, although it is known that $\mathrm{NaCl}$ is an accelerator of cement hydration, and hence lower porosity and dense pore structure are expected. $^{60,64-66}$

The phenomenon in the noncorroding specimen is attributed to the already discussed presence of certain features of the pore network, the latter not contributing to ion and water transport; hence, despite the highest porosity of $12.68 \%$ at the interface region and critical pore size of $2.8 \mu \mathrm{m}$ (Fig. 11), the noncorroding group has high resistivity (increasing from 60 to $180 \Omega \mathrm{m}$ for the bulk matrix and from 25 to $85 \Omega \mathrm{m}$ for the pore network). The corroding specimens $\mathrm{A}$ and $\mathrm{B}$ have much lower resistivity, partly denoted to the
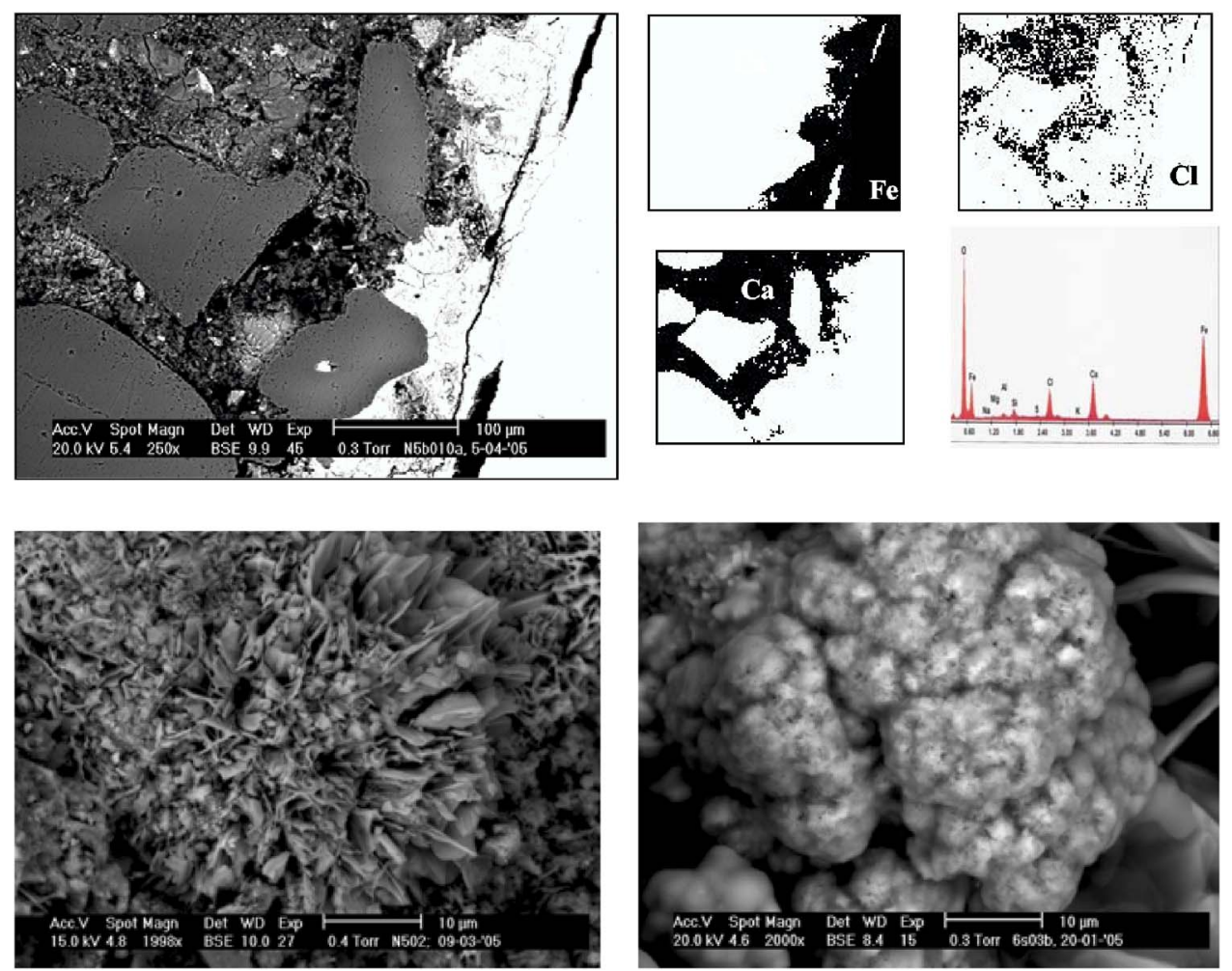

Figure 15. (Color online) Cross section (magnification $250 \times$ ) of steel/mortar interface in (left) corroding samples and (right) EDX mapping, clearly revealing the accumulation of corrosion products and chloride in the $100-200 \mu \mathrm{m}$ region close to the steel bar and lack of calcium in the $200 \mu \mathrm{m}$ region.

Figure 16. Iron oxide and oxychloride complexes of lamellar and globular morphologies, grown on the steel surface and in the vicinity of the steel/cement paste interface in the corroding specimens (group $\mathrm{N}$ ). 

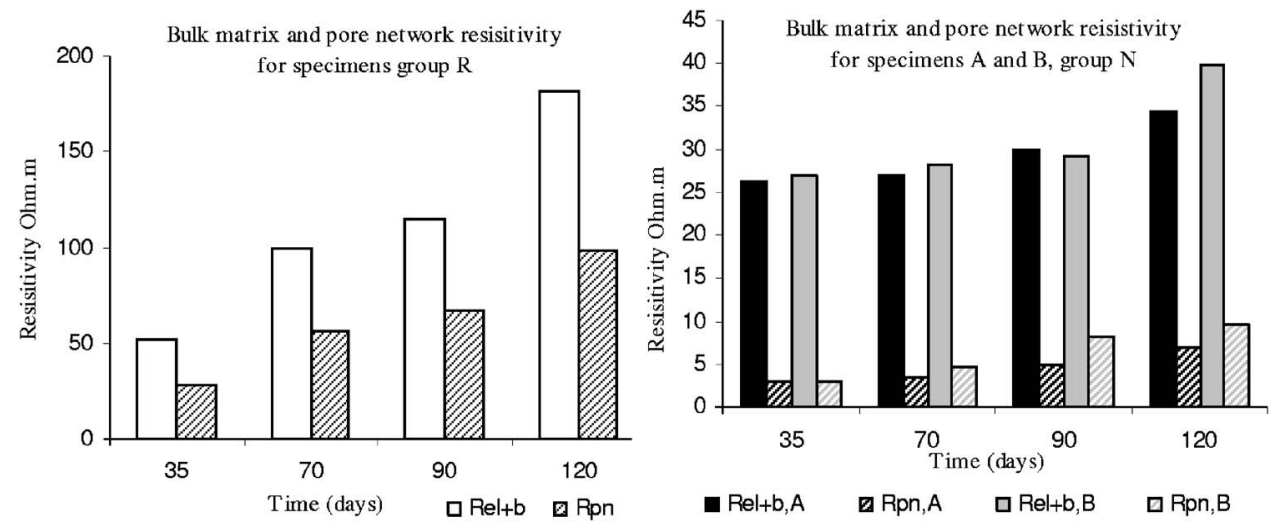

Figure 17. Evolution of bulk matrix and pore network resistivity for (left) specimens group $\mathrm{R}$ and (right) corroding specimens A and B calculated using geometrical parameters of the cell and the data obtained from EIS measurements (Table I).

presence of $\mathrm{NaCl}$. Although having the same mixture and setup, specimens A and B exhibit significant differences in microstructural parameters (Fig. 11) at the end of the test, and consequently they vary in resistivity values as well: for the bulk matrix, between 26 and $34 \Omega \mathrm{m}$ for specimen A and 26-39 $\Omega \mathrm{m}$ for specimen B (increased resistivity for specimen B at the end of the test), in accordance with the pore-network resistivity of 3-7 $\Omega \mathrm{m}$ for A and 3-10 for specimen $B$.

The resistivity values are consistent with the microstructural parameters for both specimens (Fig. 11). The interface region for specimen A is characterized by $10.87 \%$ porosity and $1.27 \mu \mathrm{m}$ critical pore size, while specimen B has lower interface porosity of $10.20 \%$ and $0.9 \mu \mathrm{m}$ critical pore size. More significant differences apply for the structural parameters at bulk and edge regions (schematic points on Fig. 1), where for specimen A, porosity is $5.2 \%$, critical pore size $0.78 \mu \mathrm{m}$, and for specimen B porosity is $1.55 \%$, with critical pore size $0.63 \mu \mathrm{m}$. The denser pore structure of specimen $\mathrm{B}$ and lower connectivity determines the higher resistivity values, compared to specimen A, although both specimens are corroding samples from one and the same group. This confirms the intimate relationship between pore structure and permeability of re- inforced cementitious materials, which determines the chloride ingress in the systems under study and the corrosion process with time, respectively.

Structural alterations relevant to the corrosion process are contributing as well; the volume of corrosion products is larger than the metallic ions, and their excessive formation results in expansive pressure and causes cracking. The newly formed cracks tend to connect with the existent cracking and form a percolated network, which in turn promotes the further ingress of chloride ion into the steel surface as expansion and cracking are multiplying the amount of connected channels for $\mathrm{Cl}^{-}$movement. This process is obviously more pronounced in specimen A than in specimen B, as connectivity in group B is lower, and consequently the structural parameters determine the electrochemical behavior to be different than group A.

The above observations on structural changes and electrical properties are supported by the OCP values (shifting of $E_{\text {corr }}$ for specimen $B$ to more noble values at the end of the test Fig. 2), the derived polarization resistance from $\mathrm{PR}$ measurements (higher $R_{p}$ for specimen B compared to specimen A at the end of the test, Fig. 3), and are evidenced by the EIS measurements, which are discussed in what follows.

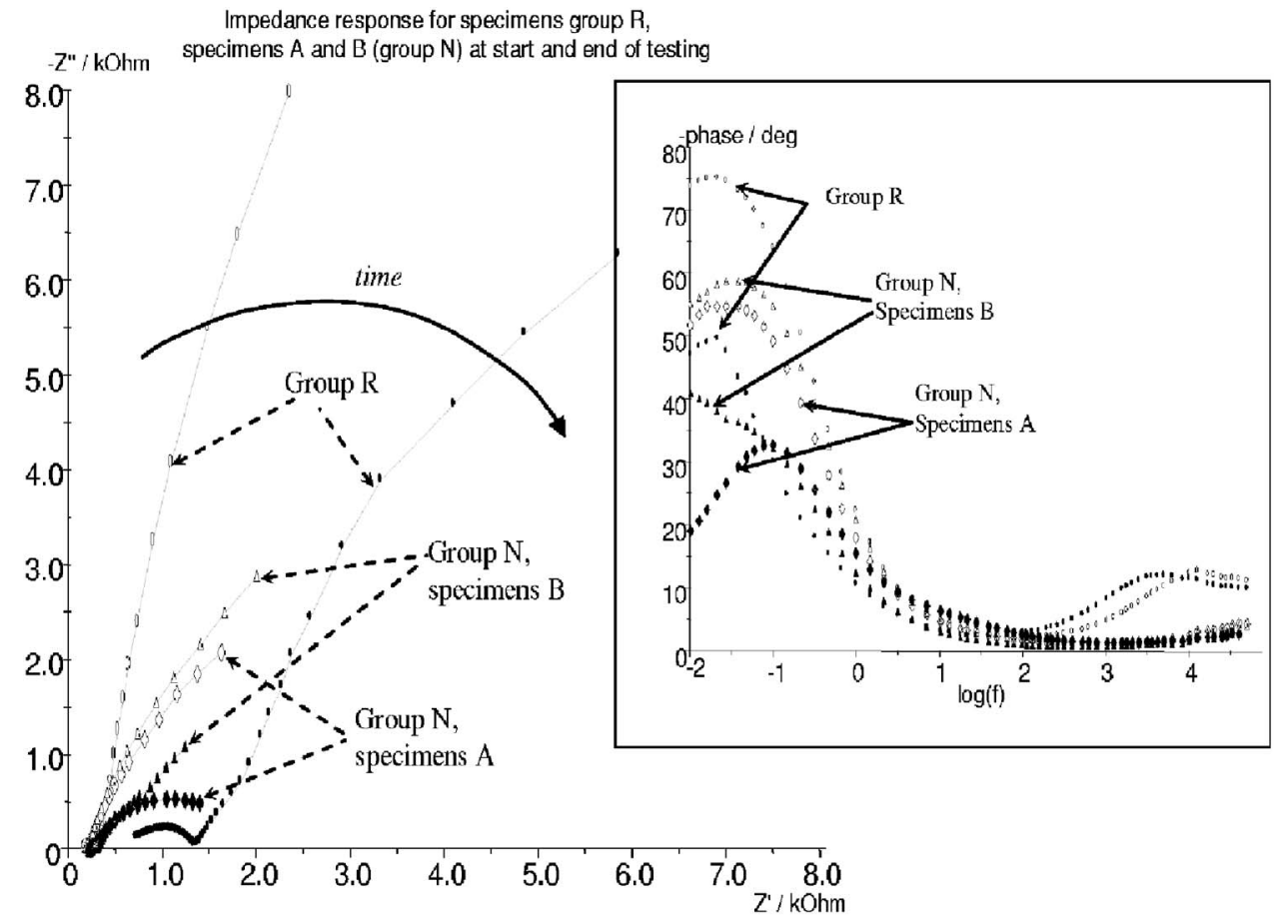

Figure 18. Comparison of EIS response in (left) Nyquist format and (incorporated right) Bode format with evolution of time for noncorroding specimens (group R) and corroding specimens A and B (group N) [(open symbols) 35 days and (solid symbols) 120 days of age]. 
Evolution of interfacial capaciatnce Cdl for specimens A and $\mathrm{B}$, group $\mathrm{N}$ and for specimens group $\mathrm{R}$

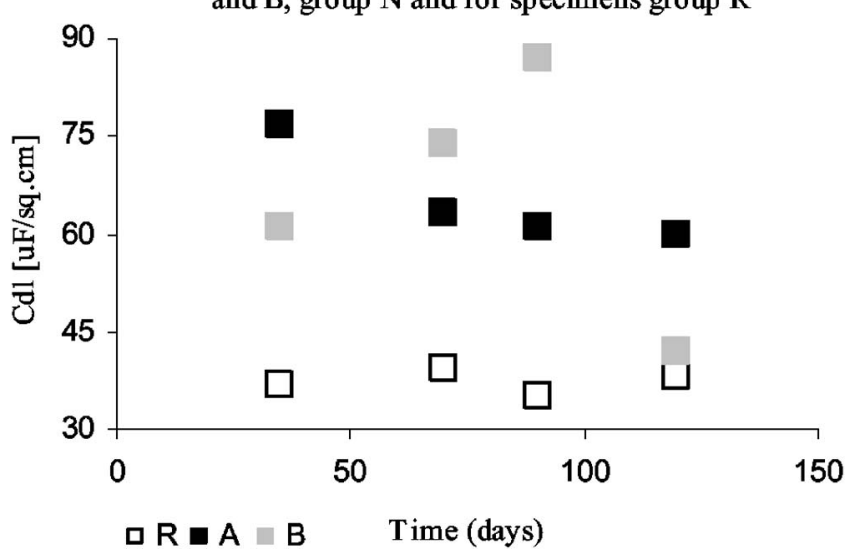

Figure 19. Evolution of interfacial capacitance with time (calculated on the basis of pseudo-capacitance in the low-frequency domain, Table I) for noncorroding group $\mathrm{R}$ and corroding specimens $\mathrm{A}$ and $\mathrm{B}$.

A comparison of the EIS response for all groups at 35 and 120 days is depicted in Fig. 18. The Nyquist diagrams for reference group $\mathrm{R}$ have a well-defined arc at high frequencies, with a change to semistraight lines (CPE with power of 0.85 to 0.87 ) at low frequency.

Although the response is not entirely capacitive, it significantly differs from the impedance response of the corroding samples, where at low frequency the shape of the diagram is a semicircle (CPE with the power of 0.6-0.8), significantly declined to the real axis of the plot. For specimen group A this shape transforms to a depressed semicircle at the end of the testing period, while for specimen $B$ a kind of transition from semicircle and semidepressed circle to a line more inclined to the imaginary axis appears. In addition, an apparent two-time constant curve and shifting of the phase angle to higher values is recorded at the end of the test. These observations are in accordance with the microstructural properties of specimen B, suggesting reduced corrosion on the steel surface as a consequence of structural and physico-chemical alterations.

Although the pseudo-capacitance on the steel surface (Table I) can provide sufficient information for the electrochemical process, in order to compare the present study with literature data, it can also be presented as double-layer capacitance [in $\mu \mathrm{F} / \mathrm{cm}^{2}$ ], using the following: ${ }^{67}$ for a given frequency $\omega$ the following relation between the imaginary part of the impedance of the CPE $\left(Z_{\mathrm{CPE}}\right)$ and the impedance of the fitted capacitance $\left(Z_{C}\right)$ is valid: $I_{m}\left(Z_{\mathrm{CPE}}\right)$ $=Z_{C} \leftrightarrow I_{m}\left[1 / Y_{o}(j \omega)^{-n}\right]=1 / j \omega C$.

Using the relationship $(j \omega)^{-n}=\omega^{-n}[\cos (-n \pi / 2)+j \sin$ $\times(-n \pi / 2)]$, the relation between the CPE parameters $Y_{o}$ and $n$ and the capacitance $C$ is $C=Y_{o} . \omega^{n-1} / \sin (n \pi / 2)$. The change of the derived capacitance values with time is depicted in Fig. 19.

The derived values for reference group $\mathrm{R}$ are almost constant with time, in the range of $37-39 \mu \mathrm{F} / \mathrm{cm}^{2}$. In contrast, the corroding specimens exhibit higher values of $C_{\mathrm{dl}}$, being in the range of $65-73 \mu \mathrm{F} / \mathrm{cm}^{2}$ average for the whole period, with an increasing trend for specimen $\mathrm{A}$ and decreasing trend for specimen $\mathrm{B}$ at the end of the period (about $42 \mu \mathrm{F} / \mathrm{cm}^{2}$ ). As mentioned, the transition in electrochemical behavior of specimen $\mathrm{B}$ is reflected also by the derived $C_{\mathrm{dl}}$, the latter showing a decreasing trend at the end of the test. The derived values for $C_{\mathrm{dl}}$ correspond well to that reported in literature for similar systems and conditions ${ }^{4,7,21,31}$ and are denoted to the electrochemical reaction on the steel surface.

\section{Conclusions}

In conclusion, the present study reveals that a combination of electrochemical and microstructural observations is a useful tool for determining the corrosion phenomena associated with reinforcement in cementitious materials. The polarization (charge-transfer) resistance reflects the electrochemical phenomena at the steel/cementpaste interface. Pore-structure investigations and quantitative-image analysis support the experimental results from EIS. Microstructural changes are a factor, significantly affecting the global performance in reinforced concrete systems and hence the electrochemical behavior of the steel surface. Moreover, it is evident that the applicability of EC techniques, EIS in particular, can supply additional information in terms of electrical properties and bulk-matrix characteristics. The correlation of corrosion behavior and derived structural and morphological characteristics provides a complete insight into the electrochemistry of the corrosion process.

\section{Acknowledgment}

The authors are grateful to M. H. J. van Maasakkers from Delft University of Technology for his professional technical support with sample preparation and SEM imaging.

Delft University of Technology assisted in meeting the publication costs of this article.

\section{References}

1. G. K. Glass and N. R. Buenfeld, Corros. Sci., 39, 1001 (1997)

2. V. Feliú, J. A. González, and S. Feliú, J. Electrochem. Soc., 151, B134 (2004).

3. K. Videm, Electrochim. Acta, 46, 3895 (2001).

4. C. Andrade, M. Keddam, X. R. Nóvoa, M. C. Pérez, C. M. Rangel, and H. Takenouti, Electrochim. Acta, 46, 3905 (2001).

5. A. A. Sagüés, M. A. Pech-Canul, and A. K. M. Shahid Al-Mansur, Corros. Sci., 45, 7 (2003).

6. M. Moreno, W. Morris, M. G. Álvarez, and G. S. Duffó, Corros. Sci., 46, 2681 (2004).

7. Y. S. Choi, J. G. Kim, and K. M. Lee, Corros. Sci., 48, 1733 (2006).

8. M. F. Montemor, A. M. P. Simões, M. M. Salta, and M. G. S. Ferreira, Corros. Sci., 35, 1571 (1993).

9. S. Feliú, J. C. Galván, S. Feliú, Jr., J. M. Bastidas, J. Simancas, M. Morcillo, and E. M. Almeida, Corros. Sci., 35, 1351 (1991).

10. R. Cigna, E. Proverbio, and G. Rocchini, Corros. Sci., 35, 1579 (1993).

11. K. Videm, Mater. Sci. Forum, 289-292, 3 (1998).

12. J. Flis, S. Sabol, H. W. Pickering, A. Sehgal, K. Osseo-Asare, and P. D. Cady, Corrosion (Houston), 49, 601 (1993).

13. V. Feliu, A. Cobo, J. A. González, and S. Feliu, Corrosion (Houston), 58, 72 (2002)

14. J. M. R. Dotto, A. G. de Abreu, D. C. C. Dal Molin, and I. L. Müller, Cem. Concr. Compos., 26, 31 (2004).

15. M. F. Montemor, M. P. Cunha, M. G. Ferreira, and A. M. Simões, Cem. Concr Compos., 24, 45 (2002)

16. V. Feliú, J. A. González, C. Andrade, and S. Feliú, Corros. Sci., 40, 975 (1998).

17. J. A. González, A. Molina, M. L. Escudero, and C. Andrade, Corros. Sci., 25, 917 (1985).

18. J. A. González, A. Molina, M. L. Escudero, and C. Andrade, Corros. Sci., 25, 519 (1985).

19. G. K. Glass and N. R. Buenfeld, Corros. Sci., 37, 1643 (1995).

20. G. K. Glass, C. L. Page, N. R. Short, and S. W. Yu, Corros. Sci., 35, 1585 (1993).

21. J. A. González, J. M. Miranda, N. Birbilis, and S. Feliú, Corrosion (Houston), 61, 37 (2005).

22. K. Videm, in Corrosion of Reinforced Concrete., No. 25, pp. 104-112, J. Mietz, B Elsener, and E. Polder, Editors, European Federation of Corrosion, London (1998).

23. N. Birbilis, B. W. Cherry, B. Gerritsen, and M. Forsyth, Paper 257 presented at 9 th International Conference on Durability of Building Materials and Components, Brisbane, Australia (2002)

24. A. Sagüés, Corrosion (Houston) 93, Paper 353, NACE Houston, TX (1993)

25. F. Mansfeld, Corrosion (Houston), 61, 739 (2005).

26. M. Stern and A. L. Geary, J. Electrochem. Soc., 104, 56 (1957).

27. J. R. Scully, Corrosion (Houston), 56, 199 (2000).

28. F. Mansfeld, Corrosion (Houston), 32, 143 (1976)

29. F. Mansfeld and M. Kendig, Corrosion (Houston), 37, 545 (1981)

30. J. A. González, J. M. Miranda, and S. Feliú, Corros. Sci., 46, 2467 (2004).

31. C. Andrade, L. Soler, C. Alonso, R. X. Nóvoa, and M. Keddam, Corros. Sci., 37, 2013 (1995).

32. O. Poupard, A. Aït-Mokhtar, and P. Dumargue, Cem. Concr. Res., 34, 991 (2004).

33. F. Wenger and J. Galland, Electrochim. Acta, 35, 1573 (1990).

34. L. Fedrizzi, F. Azzolini, and P. L. Bonora, Cem. Concr. Res., 35, 551 (2005).

35. M. Cabeza, P. Merino, A. Miranda, X. R. Nóvoa, and I. Sanchez, Cem. Concr. Res., 32, 881 (2002)

36. B. B. Hope, J. A. Page, and K. C. Alan, Cem. Concr. Res., 16, 771 (1986).

37. M. Kouřil, P. Novák, and M. Bojko, Cem. Concr. Compos., 28, 220 (2006).

38. M. Ormellese, M. Berra, F. Bolzoni, and T. Pastore, Cem. Concr. Res., 36, 536 (2006).

39. V. Saraswathy and H. W. Song, Electrochim Acta, 51, 4601 (2006).

40. C. Andrade and C. Alonso, Constr. Build. Mater, 10, 315 (1996). 
41. D. A. Koleva, J. Hu, A. L. A. Fraaij, P. Stroeven, N. Boshkov, and J. H. W. de Wit, Corros. Sci., 48, 4001 (2006).

42. C. Alonso, M. Castellote, and C. Andrade, Electrochim. Acta, 47, 3469 (2002).

43. L. Li and A. A. Sagüés, Corrosion (Houston), 57, 19 (2001).

44. J. M. Miranda, J. A. González, A. Cobo, and E. Otero, Corros. Sci., 48, 2172 (2006).

45. J. A. González, J. M. Cobo, M. N. González, and E. Otero, Mater. Corros., 51, 97 (2001).

46. A. Cobo, E. Otero, M. N. Conzalez, and J. A. González, Mater. Corros., 52, 581 (2001).

47. S. Beamish and E. B. Said, in Cathodic Protection of Steel in Concrete, P. M. Chess, Editor, E\&FN SPON, London (1998)

48. C. Andrade, F. Bolzoni, M. Cabeza, X. R. Nóvoa, and M. C. Perez, EFC, Series No. 28, The Institute of Materials, London, U.K., p. 332 (2000).

49. A. A. Sagüés, S. C. Kranc, and E. I. Moreno, Corros. Sci., 37, 1097 (1995).

50. Impedance Spectroscopy, Emphasizing Solid Materials and Systems, J. R. MacDonald, Editor, Wiley, New York (1987)

51. A. Sagüés, S. C. Kranc, and E. I. Moreno, Corrosion (Houston), 54, 20 (1988).

52. L. Dhoubi, E. Triki, and A. Raharinaivo, Cem. Concr. Compos., 24, 35 (2002).

53. M. Keddam, X. R. Nóvoa, L. Soler, C. Andrade, and H. Takenoutti, Corros. Sci., 36, 1155 (1995).
54. J. Flis, L. Dawson, J. Gill, and G. C. Wood, Corros. Sci., 32, 877 (1991).

55. J. Hu and P. Stroeven, Image Analysis and Stereology, 22, 97 (2003).

56. A. J. Katz and A. H. Thompson, J. Phys. Chem. B, 34/11, 8179 (1986)

57. P. C. Carman, J. Agric. Sci., 29, 262 (1939).

58. E. E. Underwood, Quantitative Stereology, Addison-Wesley Publishing, Reading, MA (1968).

59. J. Hu, Ph.D. Thesis, Delft University of Technology, Rotterdam: OPTIMA Grafische Communicatie (2004)

60. D. A. Koleva, J. Hu, and A. L. A. Fraaij, p. 87, C. A. Brebbia, V. G. DeGiorgy, and R. A. Adey, Editors, International Conference on Modeling Electrochemical Systems, WIT Press (2005).

61. D. A. Koleva, J. Hu, A. L. A. Fraaij, and N. Boshkov, Paper 315 presented at Eurocorr 2005, Lisbon, Portugal.

62. K. L. Scrivener, Cem. Concr. Compos., 26, 935 (2004).

63. G. K. Glass, Y. Wang, and N. R. Buenfeld, Cem. Concr. Res., 26, 1443 (1996).

64. A. K. Suryavanshi, J. D. Scantlebury, and S. B. Lyon, Cem. Concr. Res., 26, 717 (1996).

65. F. Pruckner and O. E. Gjörv, Cem. Concr. Res., 34, 1209 (2004).

66. D. M. Roy, W. Jiang, and M. R. Silsbee, Cem. Concr. Res., 30, 1879 (2000).

67. E. van Westing, Ph.D. Thesis, TNO, Delft, The Netherlands (1992). 